\title{
Spontaneous and cytokine regulated c-fos gene expression in rheumatoid synovial cells: resistance to cytokine stimulation when the c-fos gene is overexpressed
}

K Shimizu, H Kawasaki, T Morisawa, M Nakamura, E Yamamoto, N Yoshikawa, M Doita, K Shiozawa, S Yonehara, K Chihara, S Shiozawa

\begin{abstract}
Objective-To study the effect of cytokines on the transactivation of the c-fos gene in relation to the contribution of overexpression of c-fos/AP-1 in rheumatoid joint destruction.

Methods-The promoter region $(-447$ to $+109)$ of the human c-fos gene was integrated upstream of the chloramphenicol acetyltransferase (CAT) reporter gene, and the effect of cytokines on the expression of the c-fos gene was studied in the rheumatoid synovial cells of early (3-4) or late (14-18) passages, in the presence or absence of cytokines, by the transient transfection assay.

Results-Expression of c-fos gene was enhanced by tumour necrosis factor $\alpha$ (TNFo) and interleukin 6 (IL6) in the synovial cells of early passage, whereas it was not enhanced in the synovial cells of late passage. The c-fos gene expression was also enhanced by 13-O-tetradecanoyl phorbol-13-acetate (TPA) in early passage but was somewhat suppressed in the late passage. It was found that the c-fos gene and c-Fos protein were both increased in the synovial cells of late passage. Similarly, c-fos gene expression was also not increased by TPA or cytokine stimulation in the stable c-fos transformants (fospH8) or H-ras transformed NIH3T3 cells (NIH H-ras cells) that constitutively expressed c-fos genes.

Conclusions-Although TNFa and IL6 augmented c-fos gene expression of rheumatoid synovial cells, transactivation of c-fos gene became resistant against cytokine stimulation under prolonged expression of c-fos gene, which may impart a tumour-like characteristic to rheumatoid synovial cells.

(Ann Rheum Dis 2000;59:636-640)
\end{abstract}

Kyoto University

Research

$S$ Yonehara

Correspondence to:

Dr Shunichi Shiozawa, Kobe

University School of

Medicine, Faculty of Health

Science, Tomogaoka 7-10-2,

Suma-ku, Kobe 654-0142,

Japan

Email:

shiozawa@ams.Kobe-u.ac.jp

Accepted for publication 10 February 2000 duced by augmenting c-fos gene expression. ${ }^{2-6}$

As the c-fos gene has been shown to be augmented in rheumatoid joints, ${ }^{78}$ we studied the thritis of unknown cause characterised by irrethis laboratory have shown that characteristics of rheumatoid joint destruction, synovial overgrowth, and osteoporosis, especially of the juxta-articular region, are experimentally pro-
Rheumatoid arthritis (RA) is a chronic polyar- role of inflammatory cytokines in the transactivation of the c-fos gene to investigate the nature of rheumatoid synovial cells in relation to overexpression of the c-fos gene. Human c-fos gene expression was studied in rheumatoid synovial cells by transient transfection assay in the presence or absence of cytokines. The results indicated that c-fos gene expression was augmented by tumour necrosis factor $\alpha(\mathrm{TNF} \alpha)$ and interleukin-6 (IL6) in the rheumatoid synovial cells of early passage, whereas those of late passage became resistant to cytokine stimulation. This is discussed in relation to a tumour-like overgrowth of synovial cells in RA.

\section{Patients and methods}

REAGENTS

12-O-tetradecanoyl phorbol-13-acetate (TPA) was purchased from Sigma Chemical Co, MO. $\mathrm{TNF} \alpha$ and interferon $\gamma(\mathrm{IFN} \gamma)$ were obtained from Hayashibara Biochemical Co Ltd, Okayama, Japan. Interleukin $1 \beta$ (IL1 $\beta$ ) was obtained from Otsuka Pharmaceutical Factory Inc, Tokushima, Japan. Interleukin 2 (IL2) was purchased from Boehringer Mannheim $\mathrm{GmbH}$, Mannheim, Germany. Recombinant IL6 and TNF $\alpha$ were purchased from R \& D Systems, Inc (Minneapolis, MN). Rat antihuman IL6 monoclonal antibody (mAb) was purchased from Pharmingen Co Ltd San Diego, CA), and goat antihuman $\mathrm{TNF} \alpha \mathrm{mAb}$ was obtained from Genzyme Tchne Corp (Cambridge, MA).

\section{SYNOVIAL CELL CULTURE}

Synovial tissues were obtained during joint surgery from patients with RA fulfilling the diagnostic criteria of the American College of Rheumatology ${ }^{9}$ and from patients with osteoarthritis (OA). Tissues were treated with $2 \mathrm{mg} / \mathrm{ml}$ of Clostridium histolyticum collagenase (Wako Pure Chemicals, Osaka, Japan) at $37^{\circ} \mathrm{C}$ for 45 minutes, followed by treatment with $0.05 \%$ trypsin (Difco Laboratories, Detroit, Michigan, USA) at $37^{\circ} \mathrm{C}$ for 30 minutes. ${ }^{10}$ Dispersed synovial cells were placed in a $10 \mathrm{~cm}$ tissue culture dish (Iwaki Glass Co Ltd, Tokyo, Japan), and cultured overnight in Iscove's modified Dulbecco's minimal essential medium (IMDM; Gibco Laboratories, Grand Island, NY) containing $10 \%$ fetal bovine serum (FBS; Whittaker MA Bioproducts Inc, Walkersville, MD). Adherent synovial cells were harvested and passaged into another dish. Harvest and passage were repeated twice a week. For the 


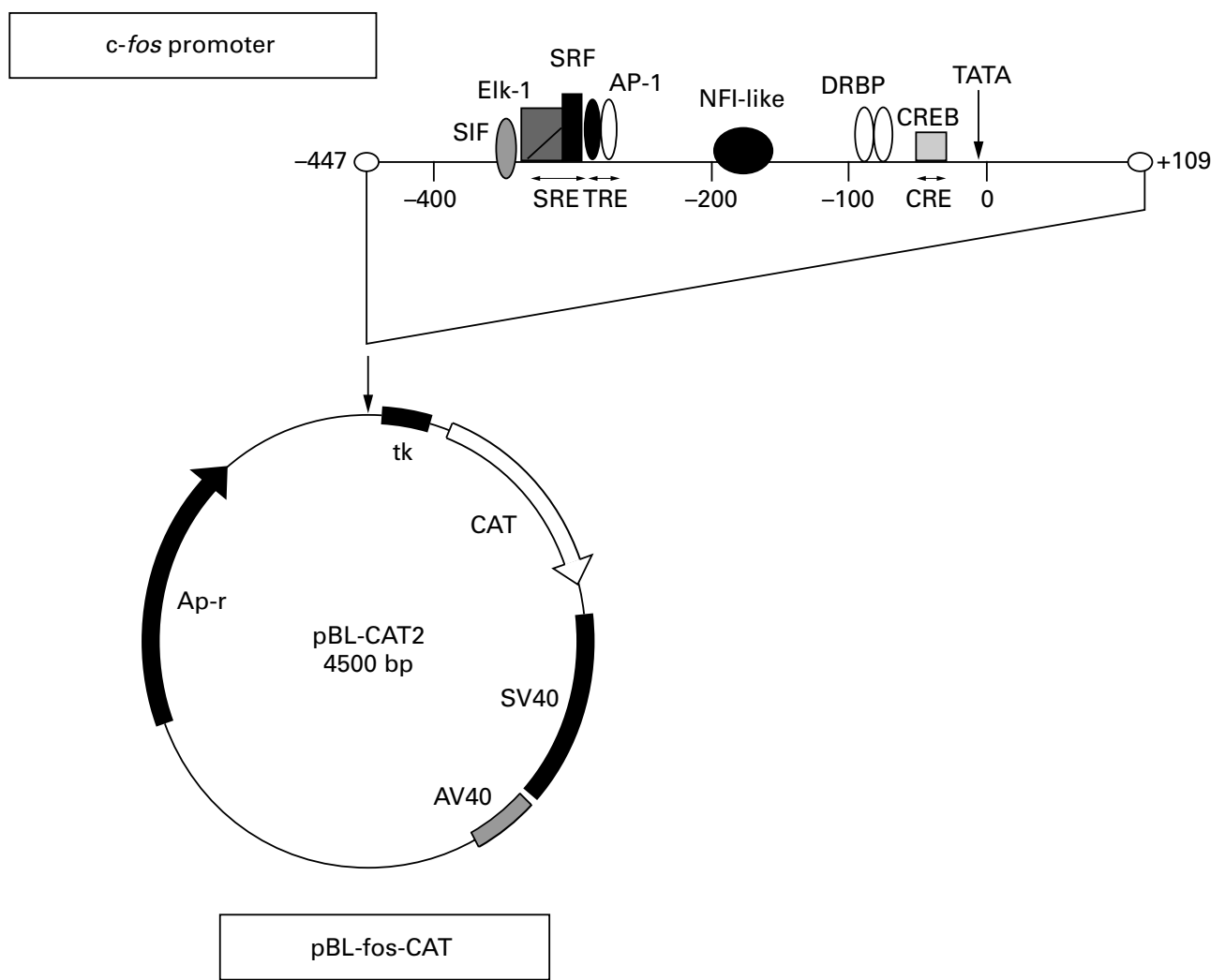

Figure 1 Human c-fos promoter (from -447 to +109 ) was integrated into $p B L-C A T 2$ plasmid to construct the CAT reporter gene ( $p B L-f o s-C A T)$. Binding sites on DNA and transcription factors were illustrated: SIF = sis (platelet derived growth factor)-induced factor; Elk-1 = $62 \mathrm{kDa}$ ternary complex factor; $S R F=$ serum response factor) $-S R E=$ serum response element; $A P-1=$ activator protein $1 ; T R E=12-O$-tetradecanoyl phorbol-13-acetate (TPA) response element; NFI-like = nuclear factor I-like binding activity; $D R B P=G C$-rich direct repeats binding protein; $C R E B=c A M P$ response element binding protein; $C R E=c A M P$ response element; TATA $=$ TATA box.

transfection study, synovial cells of early passage (3-4 passage) and late passage (14-18 passage) were used. Anti-IL6 $\mathrm{mAb}(0.1 \mu \mathrm{g} / \mathrm{ml})$ and anti-TNF $\alpha \mathrm{mAb}(0.04 \mu \mathrm{g} / \mathrm{ml})$ were added every four days.

DNA CONSTRUCT

The promoter region (from -447 to +109 ) of the human c-fos gene was amplified from genomic DNA by the polymerase chain reaction. ${ }^{11}{ }^{12}$. For the chloramphenicol acetyltransferase (CAT) enzyme linked immunosorbent assay (ELISA), the promoter was integrated into the Hind III and Bam $\mathrm{H} 1$ sites of the pBL-CAT2 bacterial CAT plasmid ${ }^{13}$ in order to locate at the upstream position of the CAT reporter gene (pBL-fos-CAT) (fig 1).

CAT ELISA ASSAY

Synovial cells were plated at $0.5 \times 10^{5}$ cells $/ 2 \mathrm{ml}$ in a $3.5 \mathrm{~cm}$ dish. When the cells became subconfluent, $1 \mu \mathrm{g}$ of DNA (pBL-fos-CAT) was transfected using lipofectin (Lipofect A; Gibco BRL, Tokyo, Japan). One day later, cells were treated with a panel of cytokines and cultured for a further 24 hours. The amount of CAT in lysed cells was measured by a CAT ELISA (Boehringer Mannheim) using a microplate reader model 550 (Nippon Bio-Rad Laboratories, Tokyo, Japan).

WESTERN BLOT ANALYSIS

Cells $\left(5 \times 10^{6}\right)$ were suspended in $100 \mu$ of lysis buffer (50 mM Tris- $\mathrm{HCl} \mathrm{pH}$ 7.5, $150 \mathrm{mM}$
$\mathrm{NaCl}, 1 \%$ Nonidet P-40, $0.5 \%$ sodium deoxycholate, $1 \mathrm{mM}$ PMSF). After sonication using Microson (MS50, Heat Systems Ultrasonics, Inc, Farmingdale, NY), the soluble fraction was obtained by centrifugation at $12000 \mathrm{rpm}$ for 10 minutes. Fifty microlitres of protein was separated using $7.5 \%$ sodium dodecyl sulphate-polyacrylamide gel electrophoresis and transferred to Immobilon-P membrane (Millipore Corp, Bedford, MA). After blocking with 3\% bovine serum albumin, the membrane was incubated with rabbit IgG anti-c-Fos antibody (sc-52; Santa Cruz Biotechnology, Inc, Santa Cruz, CA) for two hours. The membrane

Table 1 Rheumatoid synovial cells at early passage were stimulated with interferon $\gamma(I F N \gamma)$, tumour necrosis factor a (TNFa), interleukin $1 \beta$ (IL1 $\beta)$, interleukin 2 (IL2), or interleukin 6 (IL6) for 24 hours. They were assayed for $c$-fos expression in a transient assay using $p B L-f o s-C A T$

\begin{tabular}{llll}
\hline Cytokine & $10 \mathrm{U} / \mathrm{ml}$ & $50 \mathrm{U} / \mathrm{ml}$ & $100 \mathrm{U} / \mathrm{ml}$ \\
\hline Exp. 1 & & & \\
IFN $\gamma$ & $1.1^{\star}$ & 1.0 & 1.3 \\
TNF $\alpha$ & 1.2 & 1.0 & 5.6 \\
IL1 $\beta$ & 1.2 & 1.3 & 1.2 \\
IL2 & 1.1. & 1.1 & 1.1 \\
IL6 & 1.2 & 1.6 & 2.2 \\
Medium & 0.9 & & \\
Exp. 2 & & & \\
IFN $\gamma$ & 1.0 & 2.0 & 0 \\
TNF $\alpha$ & 1.2 & 10.0 & 8.2 \\
IL1 $\beta$ & 2.2 & 1.6 & 1.8 \\
IL2 & 1.6 & 0.2 & 2.0 \\
IL6 & 1.2 & 3.0 & 6.2 \\
Medium & 1.2 & & \\
\hline
\end{tabular}

${ }^{\star} \mathrm{pg} / \mathrm{ml}$ 
A

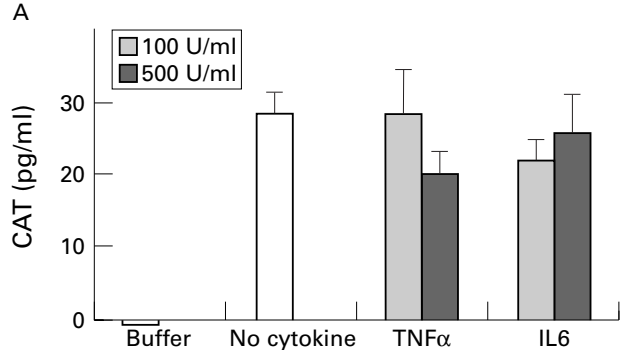

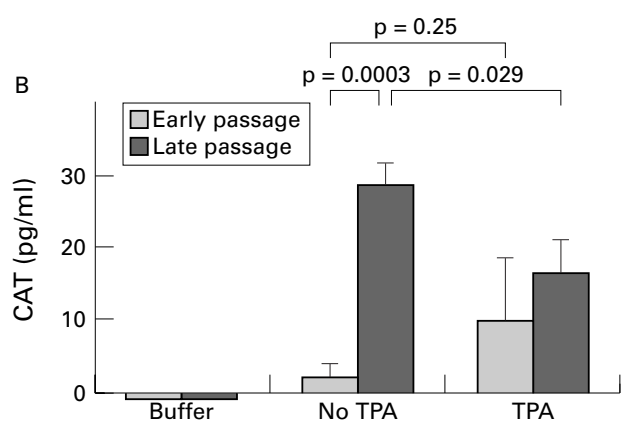

Figure 2 (A) Rheumatoid synovial cells at late passage were stimulated and assayed $(n=2)$ as described in table 1 . (B) Rheumatoid synovial cells at early passage and late passage were compared. Cells were cultured with or without $10 \mu M$ 12-O-tetradecanoyl phorbol-13-acetate (TPA) for 24 hours and assayed for chloramphenicol acetyltransferase (CAT) activity $(n=2)$.

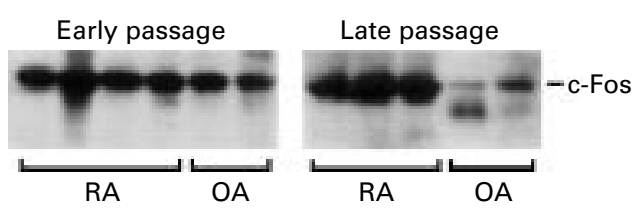

Figure 3 Western blot analyses of $c-F o$ protein in the cultured synovial cells of rheumatoid arthritis $(R A)$ and osteoarthritis $(O A)$.

was incubated with horseradish peroxidaseconjugated antirabbit IgG antibody (Amersham International, Buckinghamshire, England), and bound antibody was visualised using an enhanced chemiluminescence system (ECLTM; Amersham).

FOS-PH8 TRANSFORMANT

Cultured synovial cells $\left(1 \times 10^{6}\right)$ were suspended in $200 \mu$ of Dulbecco's phosphate buffer without calcium (Nissui Pharm. Co Ltd, Tokyo, Japan) containing $20 \mu \mathrm{g}$ of $\mathrm{pH} 8$ or fos-pH8 vectors. $^{3}$ After incubation on ice for 10 minutes, electroporation was carried out five times (five pulses) in a $2 \mathrm{~mm}$ gap cuvette at 700 $\mathrm{V}$ for $99 \mu$ s using an Electro Square Porator T820 (BTX Inc, San Diego, CA). Cells were then cultured in IMDM containing $10 \%$ FBS before selection of stable transformants by G418. Stable fos-pH8 transformants were subsequently transfected by $\mathrm{pBL}$-fos-CAT for CAT assay.

NIH H-RAS CELL

$\mathrm{H}$-ras transformed NIH3T3 cells were maintained in IMDM, ${ }^{14}$ and used for transfection experiments.
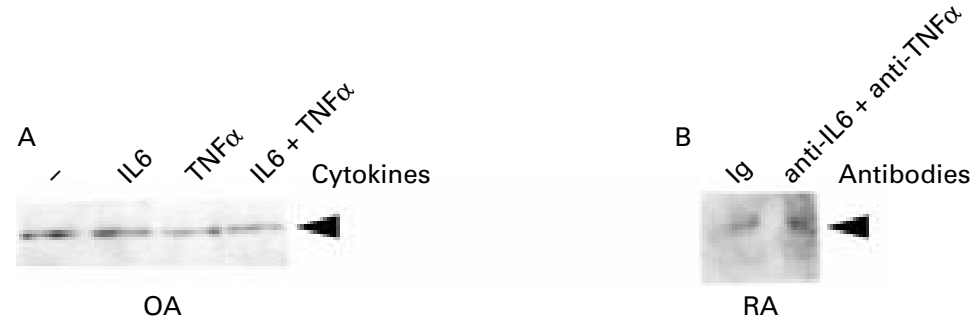

Figure 4 Western blot analyses of c-Fos protein. (A) Synovial cells of patients with osteoarthritis $(O A)$ were cultured with recombinant IL6 and TNFa for three weeks. (B) Rheumatoid synovial cells were cultured with anti-IL6 and anti-TNFa monoclonal antibody for three weeks.
STATISTICAL ANALYSIS

The data were expressed as means (standard deviation). Statistical analyses were performed using the Student's $t$ test.

\section{Results}

When synovial cells of early passage were stimulated with a panel of cytokines for 24 hours in a transient transfection assay using pBL-fos-CAT reporter, expression of the c-fos gene was enhanced by $\mathrm{TNF} \alpha$ and IL6 (table 1). However, the c-fos gene was spontaneously expressed before stimulation with cytokines when synovial cells of late passage were used (fig 2A). Synovial cells of late passage did not respond to cytokines such as IL6 or TNF $\alpha$ (fig $2 \mathrm{~A}$ ) or to cytokines such as IFN $\gamma$, IL1 $\beta$, or IL2 (not shown). The c-fos gene expression in the synovial cells of late passage was somewhat inhibited by TPA (fig 2B).

Western blot analyses showed that c-Fos protein levels were significantly increased in the rheumatoid synovial cells of late passage as compared with $\mathrm{OA}$, whereas the increase of c-Fos was less significant in the rheumatoid synovial cells of early passage (fig 3). In contrast, the c-Fos protein was decreased in the synovial cells of patients with OA at late passage, suggesting that spontaneous increase of c-Fos and its transcriptional activity was specific for RA. To test this possibility further, synovial cells of patients with OA were cultured in the presence of recombinant IL6 and TNF $\alpha$ for three weeks. The level of c-Fos protein was, however, not increased by these cytokines (fig 4). It was also found that the level of c-Fos protein was not decreased in the rheumatoid synovial cells cultured with anti-IL6 and anti$\mathrm{TNF} \alpha \mathrm{mAb}$ for three weeks (fig 4).

Contribution of the increased expression of the c-fos gene was next studied in a stable transformant containing the fos-pH8 vector. The fos-pH8 transformant overexpressing the c-fos gene showed increased transcriptional activity through the human c-fos promoter, and transactivation of the c-fos gene was somewhat inhibited by TPA which was compatible with fig $2 \mathrm{~B}$ (fig $5 \mathrm{~A}$ ). This was not the case for the control transformants containing the $\mathrm{pH} 8 \mathrm{vec}-$ tor alone (fig 5B). Expression of the c-fos gene was also studied in H-ras transformed NIH3T3 cells (NIH H-ras cells). Expression of the c-fos gene in the NIH H-ras cells was higher 
A

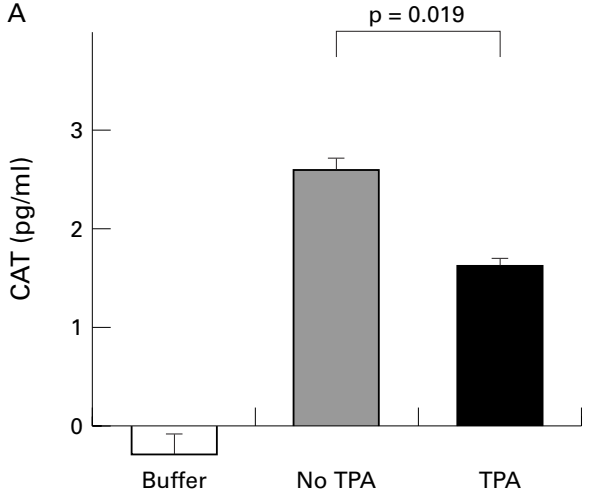

B

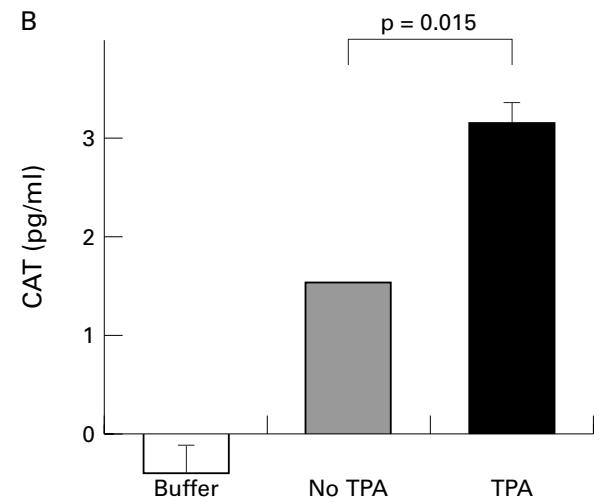

C

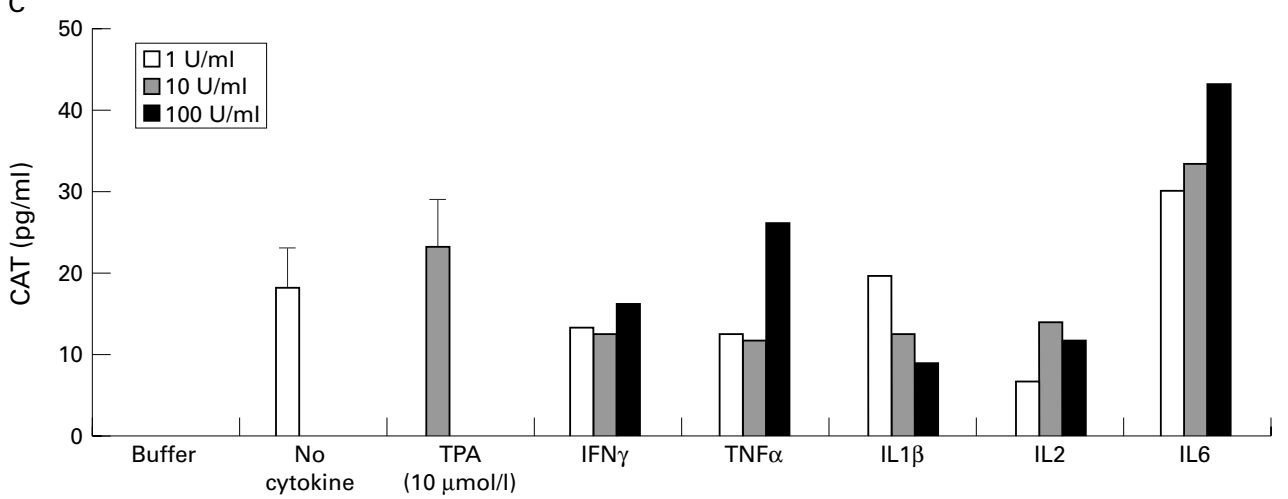

Figure 5 (A) Synovial cell transformants stably transfected with the fos-PH8 vector (fos-pH8) were stimulated with 10 $\mu M$ 12-O-tetradecanoyl phorbol-13-acetate (TPA). Expression of the c-fos gene was assessed by a chloramphenicol acetyltransferase (CAT) assay using $p B L-f o s-C A T(n=2)$. (B) Stable transformants containing the PH8 vector were assayed in an identical fashion to $(A)(n=2)$. (C) NIH H-ras cells overexpressing the c-fos gene were stimulated by cytokines for 24 hours. TPA was used at 10 umol/l. Expression of the c-fos gene was assayed in an identical fashion to (A) $(n=2)$.

because of H-ras activation. ${ }^{14}$ We found that transcriptional activation of c-fos CAT was increased in these cells (fig 5C). These cells also did not respond to stimulation with cytokines, except for a slight but insignificant increase by IL6 (fig 5C).

\section{Discussion}

Increased c-fos/AP-1 may contribute significantly to the pathogenesis of rheumatoid synovial overgrowth and joint destruction. ${ }^{1-8}$ As previous studies have shown that cytokines such as IFN $\gamma, \mathrm{TNF} \alpha$, IL1 $\beta$, IL2, or IL6 increased the expression of c-fos/AP-1, ${ }^{15-19}$ it is likely that these cytokines stimulate transactivation of c-fos/AP-1 in inflamed rheumatoid joints. Nevertheless, because this has not yet been proved, we originally undertook this study to establish the relative order of contribution of various cytokines to the transactivation of c-fos/AP-1 in the rheumatoid synovium. However, instead we found that the cells overexpressing the c-fos gene seemed to behave differently and they did not respond normally to cytokine stimulation.

We, therefore, tested the effect of various cytokines on the transactivation of the c-fos gene in a transient transfection assay using a human c-fos gene promoter integrated upstream of the CAT reporter gene. The results showed that $\mathrm{TNF} \alpha$ and IL6 augmented c-fos gene expression in rheumatoid synovial cells of early passage, indicating that these cytokines

should primarily be responsible for the transactivation of c-fos/AP-1 in rheumatoid synovium. The result is consistent with previous reports of the role of TNF $\alpha$ or IL6 in rheumatoid joint destruction. ${ }^{20}$

We have also found that rheumatoid synovial cells of late passage acquire the ability to transactivate the c-fos gene spontaneously without prior stimulation by cytokines. The cells did not respond to stimulation with inflammatory cytokines such as TNF $\alpha$ and IL6. Therefore, it was possible that c-fos gene expression had already reached a plateau in these rheumatoid synovial cells of late passage and thus they did not respond further to exogenous cytokines. Spontaneous increase of c-fos expression and c-Fos protein in rheumatoid synovial cells after long culture seemed to be specific for RA as a similar increase was not found in the synovial cells of OA. The reason for this increase is at present unclear. However, as increased levels of the c-Fos protein in rheumatoid synovial cells were not reversed by the presence of antibodies against cytokines, they seemed to be intrinsic to long cultured rheumatoid synovial cells. This finding is consistent with that of Bucala et al, who found that the proliferative capacity of conditioned media from rheumatoid synovial cells continues for a long time but gradually declines at late passage. ${ }^{21}$

We next tested whether or not the inability of synovial cells cultured for a long time to respond to cytokines was due to overexpression 
of the c-fos gene. We examined transcription of the $\mathrm{c}-f \circ$ gene in the fos-pH8 or NIH H-ras cells in which c-fos gene expression was increased. The result showed that transactivation of the c-fos gene was indeed increased in these cells and they did not respond to cytokine stimulation. It seems that synovial cells acquire some kind of resistance to cytokine stimulation, probably because of the increased c-fos gene expression. It seems interesting that, in the cells in which c-Fos was overexpressed, transcriptional activation of the c-fos gene by TPA was somewhat inhibited. As AP-1 sites should be occupied by the c-fos/AP-1 complex in the cells overexpressing the c-fos gene, signals for transactivating the c-fos gene could be rather inhibited, as was the case with glucocorticoid receptor binding on the AP-1 site. ${ }^{22}$ Therefore, overexpression of c-fos/AP-1 seems to impart a tumour-like characteristic to rheumatoid synovial cells. ${ }^{2}$

Supported in part by the grant in aid for scientific research Nos Supported in part by the grant in aid for scientific research Nos Sports and Culture of Japan.

1 Harris ED Jr. Rheumatoid arthritis: pathophysiology and implications for therapy. N Engl J Med 1990;322:1277-89.

2 Shiozawa S, Tanaka Y, Fujita T, Tokuhisa T. Destructive arthritis without lymphocyte infiltration in

3 Kuroki Y, Shiozawa S, Sugimoto T, Fujita T. Constitutive expression of c-fos gene inhibits type 1 collagen synthesis in transfected osteoblasts. Biochem Biophys Res Commun 1992;182:1389-94.

4 Kuroki Y, Shiozawa S, Yoshihara R, Hotta H. The contribution of human c-fos DNA to cultured synovial cells: a transfection study. J Rheumatol 1993;20:422-8. 5 Kuroki Y, Shiozawa S, Sugimoto T, Kanatani M, Kaji H, osteoblastic MC3T3-E1 cells stimulates osteoclast maturation and osteoclastic bone resorption. Clin Exp Immunol 1994;95:536-9.

6 Shiozawa S, Shimizu K, Tanaka K, Hino K. Studies on the contribution of c-fos/AP-1 to arthritic joint destruction. J contribution of c-fos/AP-1 to
Clin Invest 1997;99:1210-16.

7 Trabandt A, Aicher WK, Gay RE, Sukhatme VP, Fassbender HG, Gay S. Spontaneous expression of immediately-early response genes c-fos and erg-1 in collagenase-producing rheumatoid synovial fibroblasts. Rheumatol Int 1992;12:53-9.
8 Asahara H, Fujisawa K, Kobata T, Hasunuma T, Maeda T, Asanuma $M$, et al. Direct evidence of high DNA binding
activity of transcription factor AP- 1 in rheumatoid arthritis activity of transcription factor AP-1 in rheumato
synovium. Arthritis Rheum 1997;40:912-18.

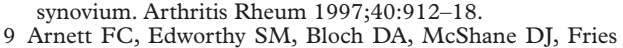
$\mathrm{JF}$, Cooper NS, et al. The American Rheumatism Association 1987 revised criteria for the classification of rheumatoid arthritis. Arthritis Rheum 1988;31:315-24.

10 Shimizu S, Shiozawa S, Shiozawa K, Imura S, Ishikawa $H$, Hirohata $\mathrm{K}$, et al. The restoration of proliferation and differentiation of peripheral blood mononuclear nonadherent cells into immunoglobulin-secreting cells by autologous synovial adherent cells from patients with rheuautologous synovial adherent cells from patients with rheumatoid

11 Straaten FV, Muller R, Curran T, Beveren CV, Verma IM. Complete nucleotide sequence of a human c-onc gene: deduced amino acid sequence of the human c-fos protein. Proc Natl Acad Sci USA 1983;80:3183-7.

12 Hipskind RA, Nordheim A. Functional dissection in vitro of the human c-fos promoter. J Biol Chem 1991;266:1958392.

13 Angel P, Imagawa M, Chiu R, Stein B, Imbra RJ, Rahmsdorf $\mathrm{HJ}$, et al. Phorbol ester-inducible genes contain a common cis element recognized by a TPA-modulated trans-acting cis element recognized by a
factor. Cell 1987;49:729-39.

14 Hotta S, Miyamoto H, Hara H, Takahashi N, Homma M. Genomic structure of the ME491/CD63 antigen gene and functional analysis of the 5'-flanking regulatory sequences. Biochem Biophys Res Commun 1992;185:436-42.

15 Angel P, Karin M. The role of Jun, Fos and the AP-1 complex in cell-proliferation and transformation. Biochim Biophys Acta 1991;1072:129-57.

16 Jenab S, Morris PL Transcriptional regulation of Sertoli cell immediate early gene by interleukin- 6 and interferon- $\gamma$ is mediated through phosphorylation of STAT- 3 and is mediated through phosphorylation of STAT-3
STAT-1 proteins. Endocrinology 1997;138:2740-6.

17 Bruccoleri A, Gallucci R, Germolec DR, Blackshear P, Simeonova P, Thurman RG, et al. Induction of earlyimmediate genes by tumor necrosis factor $\alpha$ contributes to liver repair following chemical-induced hepatotoxicity. Hepatology 1997;25:133-41.

18 Reddy SA, Huang JH, Liao WS. Phosphatidylinositol 3-kinase in interleukin 1 signaling. Physical interaction with the interleukin 1 receptor and requirement in NF kappa B and AP-1 activation. I Biol Chem 1997;272: kappa B and 73 .

19 Pereda MP, Goldberg V, Chervin A, Carrizo G, Molina A, Andrada $\mathrm{J}$, et al. Interleukin-2 (IL-2) and IL-6 regulate c-fos protooncogene expression in human pituitary adenoma explants. Mol Cell Endocrinol 1996;124:33-42.

20 Arend WP, Dayer J-M. Inhibition of the production and effects of interleukin-1 and tumor necrosis factor $\alpha$ in rheumatoid arthritis. Arthritis Rheum 1995;38:151-60.

21 Bucala R, Ritchlin C, Winchester R, Cerami A. Constitutive production of inflammatory and mitogenic cytokines by rheumatoid synovial fibroblasts. J Exp Med 1991;173:56974.

22 Karagianni N, Tsawdaroglou N. The c-fos serum response element (SRE) confers negative response to glucocorticoids. Oncogene 1994;9:2327-34. 